\title{
TEOREMA TITIK TETAP FUNGSI YANG KONTRAKSI TEGAS
}

\author{
Michael Inuhan ${ }^{1}$, Ch. Rini Indrati ${ }^{2}$ \\ ${ }^{1,2}$ Department of Mathematics, Gajah Mada University, Yogyakarta, Indonesia \\ Email :1michael.inuhan@mail.ugm.ac.id,2rinii@ugm.ac.id
}

\begin{abstract}
In this paper, it will be discussed some fixed point theorems in ultrametric spaces. By using spherically complete properties, it can be shown that there exists a unique fixed point of strictly contractive function. At the end, it will be shown there exists fixed point of strictly contracting on orbits function.
\end{abstract}

Keywords: ultrametric space, fixed point, strictly contractive, strictly contracting on orbits.

\begin{abstract}
Abstrak. Pada tulisan ini, akan dibahas beberapa teorema titik tetap pada ruang ultrametrik. Dengan menggunakan sifat bola terbuka, dapat ditunjukkan terdapat dengan tunggal titik tetap fungsi yang kontraksi tegas. Pada akhir tulisan ini, akan ditunjukkan terdapat titik tetap fungsi yang kontraksi tegas pada orbit.
\end{abstract}

Keywords: ruang ultrametrik, titik tetap, kontraksi tegas, kontraksi tegas pada orbit.

\section{PENDAHULUAN}

Pada teori titik tetap, terdapat prinsip yang dikenal dengan Prinsip Kontraksi Banach (Banach's Contraction Principle). Dalam [4], prinsip kontraksi Banach menggunakan konsep ruang metrik. Seiring dengan perkembangan penelitian tentang ruang metrik, ditemukan suatu sifat yang dikenal sebagai sifat ketaksamaan segitiga kuat (strong triangle inequality). Ruang metrik yang memenuhi sifat ketaksamaan segitiga kuat disebut ruang ultrametrik [1]. Pada ruang ultrametrik, setiap bola terbuka (open ball) merupakan himpunan tertutup dan bola tertutup (closed ball) merupakan himpunan terbuka. Selain itu, terdapat prinsip segitiga sama-kaki (isosceles triangles) dan sifat bola lengkap (spherically complete) yang tidak dijumpai pada ruang metrik yang bukan ultrametrik [8].

Untuk sebarang ruang ultrametrik dengan sifat bola lengkap $(X, d)$ dan fungsi nonekspansif $f: X \rightarrow X$ berlaku setiap bola $B[x, d(x, f(x))]$ memuat titik tetap $f$ atau memuat bola yang invarian minimal terhadap $f$ (minimal invariant of $f$ ) [2]. Akibatnya, terdapat dengan tunggal titik tetap fungsi yang kontraksi tegas (strictly contractive) [5]. Setiap fungsi yang kontraksi tegas merupakan fungsi yang kontraksi tegas pada orbit (strictly contracting on orbits), namun belum tentu berlaku sebaliknya [3]. Dalam mempelajari teori titik tetap fungsi yang kontraksi tegas pada orbit, dibutuhkan teorema yang dikenal dengan Teorema Titik Tetap Kuat (Strong Fixed Point Theorem) [6].

Selanjutnya, pada tulisan ini akan ditunjukkan bahwa pad ruang ultrametrik berlaku, setiap fungsi yang kontraksi tegas merupakan fungsi yang non-ekspansif. Kemudian, dengan menggunakan teorema titik tetap kuat, dapat ditunjukkan setiap fungsi non-ekspansif pada ruang ultrametrik dengan sifat bola lengkap memiliki titik tetap. Pada akhir tulisan ini, akan diberikan suatu syarat, agar setiap fungsi yang kontraksi tegas pada orbit merupakan fungsi kontraksi tegas. 


\section{RUANG ULTRAMETRIK}

Berikut ini akan diulas kembali beberapa konsep pada ruang ultrametrik yang akan digunakan untuk menunjukkan hasil utama. Konsep ruang metrik merupakan salah satu konsep dasar dalam matematika, khususnya dalam bidang analisis. Ruang metrik $(X, d)$ disebut ruang ultrametrik jika metrik $d$ memenuhi sifat ketaksamaan segitiga kuat (strong triangle inequality).

Definisi 2.1.[1] Ruang metrik $(X, d)$ dikatakan memenuhi sifat ketaksamaan segitiga kuat (strong fixed point theorem) jika untuk setiap $x, y, z \in X$ berlaku,

$$
d(x, y) \leq \max \{d(x, z), d(z, y)\}
$$

Ruang metrik yang memenuhi sifat ketaksamaan segitiga kuat disebut ruang ultrametrik. Diperhatikan ruang metrik $\mathbb{R}$ dilengkapi dengan metrik biasa (usually metric), tidak memenuhi sifat ketaksamaan segitiga kuat. Dengan demikian, setiap ruang ultrametrik merupakan ruang metrik namun belum tentu berlaku sebaliknya. Beberapa sifat yang membedakan ruang ultrametrik dengan ruang metrik yang bukan ultrametrik dapat dilihat pada karakteristik bola terbuka dan tertutup pada ruang ultrametrik.

Definisi 2.2. [9] Diberikan ruang metrik $(X, d)$ dan $x \in X$.

1. Himpunan $B(x, r)=\{y \in X \mid d(x, y)<r, r>0\}$ disebut bola terbuka (open ball).

2. Himpunan $B[x, r]=\{y \in X \mid d(x, y) \leq r, r \geq 0\}$ disebut bola tertutup (closed ball). Dalam hal $r=0, B[x, r]=\{x\}$.

Karena ruang ultrametrik merupakan ruang metrik, maka definisi bola terbuka dan bola tertutupnya sama dengan pada ruang metrik. Pada Teorema 1.3 berikut, akan ditunjukkan beberapa karakteristik bola terbuka dan tertutup yang hanya ada pada ruang ultrametrik.

Teorema 2.3.[8] Diberikan ruang ultrametrik $(X, d)$ dan $x \in X$.

1. Setiap titik pada bola terbuka merupakan pusat bola.

2. Jika untuk setiap $x, y \in X$ dan $r, s>0$ berlaku $B(x, r) \cap B(y, s) \neq \emptyset$, maka $B(x, r) \subseteq B(y, s)$ atau $B(y, s) \subseteq B(x, r)$.

3. Setiap bola terbuka merupakan himpunan tertutup dan terbuka.

Selanjutnya, metrik pada ruang ultrametrik memenuhi prinsip segitiga sama-kaki (isosceles triangle principle). Ruang ultrametrik $(X, d)$ dikatakan memenuhi prinsip segitiga sama-kaki jika untuk setiap $x, y, z \in X$ yang memenuhi $d(x, z) \leq d(z, y)$ dan $d(x, y)<\max$ $\{d(x, z), d(z, y)\}$, berlaku

$$
d(x, z)<d(z, y) \text {. }
$$

Salah satu sifat yang penting pada ruang ultrametrik adalah sifat bola lengkap (spherically complete).

Definisi 2.4.[8] Ruang ultrametrik $(X, d)$ dikatakan memiliki sifat bola lengkap jika untuk setiap koleksi $\left\{B_{i}=B\left[x_{i}, r_{i}\right] \mid i \in I\right\}$ dengan $r_{1} \geq r_{2} \geq \cdots$ dan $B_{1} \supseteq B_{2} \supseteq \cdots$ berlaku $\bigcup_{i \in I} B_{i} \neq \varnothing$. 


\section{EKSISTENSI DAN KETUNGGALAN TITIK TETAP FUNGSI YANG KONTRAKSI TEGAS}

Diberikan ruang ultrametrik $(X, d)$. Fungsi $f: X \rightarrow X$ dikatakan non-ekspansif (nonexpansive) jika untuk setiap $x, y \in X$ berlaku, $d(f(x), f(y)) \leq d(x, y)$ [4]. Selanjutnya, akan diberikan definisi fungsi yang kontraksi tegas (strictly contractive) sebagai berikut.

Definisi 3.1.[8] Diberikan ruang ultrametrik $(X, d)$. Fungsi $f: X \rightarrow X$ dikatakan kontraksi tegas jika untuk setiap $x, y \in X$ dengan $x \neq y$ berlaku, $d(f(x), f(y))<d(x, y)$.

Berdasarkan definisi fungsi yang kontraksi tegas dan fungsi yang non-ekspansif, dapat ditunjukkan semua fungsi yang kontraksi tegas merupakan fungsi non-ekspansif.

Teorema 3.2. Diberikan ruang ultrametrik $(X, d)$ dan fungsi $f: X \rightarrow X$. Jika fungsi $f$ kontraksi tegas, maka $f$ non-ekspansif.

\section{Bukti.}

Diambil sebarang $x, y \in X$. Diperhatikan bahwa, untuk $x=y$, diperoleh $f(x)=f(y)$. Akibatnya, $d(f(x), f(y))=0=d(x, y)$. Selanjutnya, karena $f$ kontraksi, maka untuk $x \neq$ $y$, diperoleh $d(f(x), f(y))<d(x, y)$.

Selanjutnya, untuk menunjukkan eksistensi dan ketunggalan titik tetap fungsi yang kontraksi tegas, diperlukan definisi bola yang invarian minimal (minimal invariant).

Definisi 3.3.[2] Diberikan ruang ultrametrik $(X, d)$ dan fungsi $f: X \rightarrow X$. Bola $B[x, r]$ dengan $x \in X$ dan $r>0$ dikatakan invarian minimal terhadap $f$ jika $f(B[x, r]) \subseteq B[x, r]$ dan $d(u, f(u))=r$, untuk setiap $u \in B[x, r]$.

Berikut teorema yang akan digunakan untuk membuktikan eksistensi dan ketunggalan titik tetap fungsi yang kontraksi tegas. Untuk buktinya merujuk pada [2].

Teorema 3.4. Diberikan ruang ultrametrik dengan sifat bola lengkap $(X, d)$ dan fungsi $f: X \rightarrow X$. Jika $f$ non-ekspansif, maka untuk setiap $x \in X$, berlaku bola $B[x, d(x, f(x))]$ memuat titik tetap $f$ atau bola yang invarian minimal terhadap $f$.

Berdasarkan Teorema 3.4 diperoleh Akibat 3.5.

Akibat 3.5. Jika $(X, d)$ ruang ultrametrik dengan sifat bola lengkap dan fungsi $f: X \rightarrow X$ kontraksi tegas, maka terdapat dengan tunggal titik tetap $f$ di $X$.

\section{Bukti.}

Andaikan $f$ tidak mempunyai titik tetap di $X$. Berdasarkan Teorema 2.4 diperoleh untuk setiap bola $B[x, d(x, f(x))]$ memuat bola yang invarian minimal terhadap $f$. Akibatnya, terdapat $B[z, r] \subseteq B[x, d(x, f(x))]$ sehingga untuk setiap $u \in B[z, r]$ berlaku $f(u) \in B[z, r]$ dan $d(u, f(u))=r$. Diperoleh $d\left(f(u), F^{2}(u)\right)=r \quad$ dan $\quad d(u, f(u))=r$. Akibatnya, 
$d\left(f(u), f^{2}(u)\right)=d(u, f(u))$. Kontradiksi dengan $f$ kontraksi tegas. Dengan demikian pengandaian salah, dengan kata lain $f$ mempunyai titik tetap di $B[x, d(x, f(x))]$.

Selanjutnya, akan ditunjukkan ketunggalan titik tetap. Andaikan terdapat $x, y \in X$ titik tetap $f$ dengan $x \neq y$. Diperoleh $d(f(x), f(y))=d(x, y)$ kontradiksi dengan $d(f(x), f(y))<d(x, y)$. Dengan demikian pengandaian salah. Jadi, $x=y$.

\section{EKSISTENSI DAN KETUNGGALAN TITIK TETAP FUNGSI YANG KONTRAKSI TEGAS}

Diberikan ruang ultrametrik $(X, d)$ dan fungsi $f: X \rightarrow X$. Orbit $x$ terhadap fungsi $f$ adalah barisan $\left\{f^{n}(x) \mid n=0,1,2, \cdots\right\}$ dengan $f^{0}(x)=0$ [7]. Selanjutnya, akan ditunjukkan eksistensi titik tetap fungsi yang kontraksi tegas pada orbit (strictly contracting on orbits). Sebelumnya, diberikan definisi fungsi yang kontraksi tegas pada orbit sebagai berikut.

Definisi 4.1.[3] Diberikan ruang ultrametrik $(X, d)$. Fungsi $f: X \rightarrow X$ dikatakan kontraksi tegas pada orbit jika untuk setiap $x \in X$ dengan $x \neq f(x)$ berlaku, $d\left(f^{2}(x), f(x)\right)<$ $d(f(x), x)$.

Dengan menggunakan sifat segitiga sama kaki pada ruang ultrametrik, diperoleh Teorema 4.2.

Teorema 4.2. Diberikan ruang ultrametrik $(X, d)$. Jika fungsi $f: X \rightarrow X$ kontraksi tegas pada orbit, maka untuk setiap $x \in X$ dengan $x \neq f(x)$, berlaku $d\left(f^{2}(x), x\right)=d(f(x), x)$.

\section{Bukti.}

Diambil sebarang $x \in X$ dengan $x \neq f(x)$. Karena $f$ kontraksi tega pada orbit, maka $d\left(f^{2}(x), f(x)\right)<d(f(x), x)$. Akibatnya, $d\left(f^{2}(x), f(x)\right)<\max \left\{d\left(f^{2}(x), x\right), d(x, f(x))\right\}$. Berdasarkan sifat segitiga sama kaki pada ruang ultrametrik, maka diperoleh

$$
d\left(f^{2}(x), f(x)\right)=d(f(x), x) .
$$

Berdasarkan Definisi 4.1 jelas bahwa, kontraksi tegas pada orbit merupakan perumuman kontraksi tegas.

Teorema 4.3.[3] Diberikan ruang ultrametrik $(X, d)$. Jika fungsi $f: X \rightarrow X$ kontraksi tegas, maka $f$ kontraksi tegas pada orbit.

Berdasarkan Teorema 4.3 dapat dilihat bahwa setiap fungsi yang kontraksi tegas merupakan fungsi yang kontraksi tegas pada orbit, namun tidak selalu berlaku sebaliknya. Hal tersebut dapat dilihat pada contoh berikut.

Contoh 4.4. Diberikan himpunan $X=\{a, b, c, d\}$ dan $d: X \rightarrow X$ dengan definisi $d(x, x)=0$ untuk setiap $x \in X, \quad d(a, b)=d(c, d)=\frac{1}{2}, \quad d(a, c)=d(b, d)=d(b, c)=d(a, d)=1$, $d(x, y)=d(y, x)$ untuk setiap $x, y \in X$. Diperhatikan himpunan $X$ dilengkapi dengan metrik $d$ merupakan ruang ultrametrik. Lebih lanjut, fungsi $f: X \rightarrow X$ dengan $f(a)=a, f(b)=$ $b, f(c)=a, f(d)=b$, merupakan fungsi yang kontarksi tegas pada orbit tetapi tidak kontraksi tegas. 
Untuk membuktikan eksistensi teorema titik tetap fungsi yang kontraksi tegas pada orbit, diperlukan suatu teorema yang disebut Teorema Titik Tetap Kuat (Strong Fixed Point Theorem). Untuk bukti teorema titik tetap kuat merujuk pada [6].

Teorema 4.5. (Teorema Titik Tetap Kuat) Diberikan ruang ultrametrik dengan sifat bola lengkap $(X, d)$ dan fungsi $f: X \rightarrow X$. Jika $f$ memenuhi sifat berikut:

1. Jika $z \neq f(z)$ dan $d(x, f(z)) \leq d\left(f^{2}(z), f(z)\right)$, maka $d(x, f(x)) \leq d(z, f(z))$, dan

2. Fungsi $f$ kontraksi tegas pada orbit,

maka $f$ memiliki titik tetap.

Berdasarkan Teorema 3.4 diperoleh Akibat 3.5.

Akibat 4.6. Diberikan ruang ultrametrik dengan sifat bola lengkap $(X, d)$ dan fungsi nonekspansif $f: X \rightarrow X$. Jika $f$ kontraksi tegas pada orbit, maka terdapat titik tetap $f$ di $X$.

\section{Bukti.}

Andaikan $f$ tidak memiliki titik tetap, artinya untuk setiap $x \in X$ berlaku $f(x) \neq x$. Jika untuk setiap $x, z \in X$ berlaku $d(x, f(z)) \leq d\left(f^{2}(z), f(z)\right)$, akan ditunjukkan $d(x, f(x)) \leq$ $d(z, f(z)$. Diambil sebarang $x, z \in X$, diperoleh

$$
\begin{aligned}
d(x, f(x)) & \leq \max \{d(x, f(z)), d(f(z), f(x))\} \\
& \leq \max \{d(x, f(z)), d(f(z), z), d(z, f(x))\} \\
& \leq \max \left\{d\left(f^{2(z)}, f(z)\right), d(z, f(z))\right\} \leq d(f(z), z) .
\end{aligned}
$$

Dengan demikian fungsi $f$ memenuhi kondisi 1 dan 2 pada Teorema 3.5. Akibatnya, $f$ memiliki titik tetap.

Berdasarkan Teorema 3.3, diperoleh fungsi yang kontraksi tegas merupakan fungsi yang kontraksi tegas pada orbit, namun belum tentu berlaku sebaliknya. Supaya dapat berlaku sebaliknya, maka diberikan kondisi sebagaimana pada Teorema 3.7 berikut.

Teorema 4.7. Diberikan ruang ultrametrik dengan sifat bola lengkap $(X, d)$ dan fungsi nonekspansif $f: X \rightarrow X$. Jika untuk setiap $x, y \in X$ dengan $x \neq y$ berlaku $d(f(x), x) \leq d(x, y)$, maka kedua pernyataan berikut saling ekuivalen,

1. Fungsi f kontraksi tegas.

2. Fungsi $f$ kontraksi tegas pada orbit dan memiliki titik tetap tunggal di X.

\section{Bukti.}

$(1 \Rightarrow 2)$ Berdasarkan Teorema 3.3 dan Akibat 2.5, diperoleh $f$ kontraksi tegas pada orbit dan memiliki titik tetap tunggal.

$(2 \Rightarrow 1)$ Diambil sebarang $x, y \in X$ dengan $x \neq y$, diperoleh

$$
\begin{aligned}
d(f(x), f(y)) \leq & \max \left\{d\left(f(x), f^{2}(x)\right), d\left(f^{2}(x), f^{2}(y)\right), d\left(f^{2}(y), f(y)\right)\right\} \\
& <\max \{d(x, f(x)), d(x, y), d(f(y), y)\} \\
& =d(x, y) .
\end{aligned}
$$

Dengan demikian, $f$ kontraksi tegas. 


\section{KESIMPULAN}

Fungsi $f: X \rightarrow X$ yang kontraksi tegas dengan $X$ ruang ultrametrik dengan sifat bola lengkap, memiliki titik tetap tunggal di $X$. Setiap fungsi yang kontraksi tegas merupakan fungsi yang kontraksi tegas pada orbit. Fungsi $f: X \rightarrow X$ yang kontraksi tegas dengan $X$ ruang ultrametrik dengan sifat bola lengkap, memiliki titik tetap di $X$.

\section{REFERENSI}

[1] A Lemin, "On Ultrametrization of General Metric Spaces," Proceedings American Mathematical Society, vol. 131, no. 3, pp. 979-989, October 2002.

[2] C Petalas and T Vidalis, "A Fixed Point Theorem in Non-archimedean Vector Spaces," Proceedings of the American Mathematical Society, vol. 118, no. 3, pp. 819-821, July 1993.

[3] E Matsikoudis and Edward A Lee, "The Fixed Point Theory of Strictly Contracting Functions on Generalized Ultrametric Semilattices," Fixed Point in Computes Science, vol. 126, no. 5, pp. 56-71, - 2013.

[4] Ravi P Agarwal, Maria Meehan, and Donal O'regan, Fixed Point Theory and Applications, 1st ed., B Bollobas, Ed. Cambridge, United Kingdom: Cambridge University Press, 2004.

[5] S Priess-Crampe, "Der Banachsche Fixpunktsatz fur Ultrametrische Raume," Results Math, vol. 18, no. 1-2, pp. 178-186, - 1990.

[6] S Priess-Crampe and P Ribenboim, "Fixed Point and Attactor Theorems for Ultrametric Spaces," Forum Math, vol. 12, no. -, pp. 53-64, - 2000.

[7] S Rolewicz, "On Orbits of Element," Studia Mathematica, vol. 32, no. -, pp. 17-22, 1969.

[8] W. A Kirk and N Shahzad, "Some Fixed Point Results in Ultrametric Spaces," Elsevier, vol. 159, no. -, pp. 3327-3334, July 2012.

[9] W. H Schikhof, Ultrametric Calculus, 1st ed., D. J. H Garling and D Gorenstein, Eds. Cambridge, United Kingdom: Cambridge University Press, 1984. 